\title{
Selected current-use pesticides (CUPs) in coastal and offshore sediments of Bohai and Yellow seas
}

\author{
Guangcai Zhong • Jianhui Tang • Zhiyong Xie • \\ Wenying Mi • Yingjun Chen • Axel Möller • \\ Renate Sturm • Gan Zhang • Ralf Ebinghaus
}

Received: 21 November 2013 / Accepted: 10 February 2014/Published online: 2 March 2014

(C) Springer-Verlag Berlin Heidelberg 2014

\begin{abstract}
China is one of the largest producers, consumers, and traders for pesticides in the world. Currently, there are more than 600 pesticide-active substances registered in China, whereas few studies were conducted to improve our understanding of the occurrence and environmental impact of current-use pesticides (CUPs) in China's environment. In this work, 72 surface sediment samples were taken from the coastal and offshore of Bohai and Yellow seas and were analyzed for six CUPs (trifluralin, dacthal, quintozene, endosulfan, chlorpyrifos, and dicofol) and two metabolites (pentachloroanisole and endosulfan sulfate). Sediment samples were categorized as estuarine or near-shore sediments (Laizhou Bay, Taozi Bay, Sishili Bay, and Jiaozhou Bay) and offshore sediments. Trifluralin, $\alpha$ endosulfan, endosulfan sulfate, chlorpyrifos, dicofol, and
\end{abstract}

Responsible editor: Ester Heath

Electronic supplementary material The online version of this article (doi:10.1007/s11356-014-2648-7) contains supplementary material, which is available to authorized users.

\section{G. Zhong $\cdot$ J. Tang $(\bowtie) \cdot$ Y. Chen}

Key Laboratory of Coastal Environmental Processes and Ecological Remediation, Yantai Institute of Coastal Zone Research, Chinese Academy of Sciences, Yantai 264003, China

e-mail: jhtang@yic.ac.cn

G. Zhong $\cdot$ Z. Xie $\cdot$ W. Mi · A. Möller $\cdot$ R. Sturm $\cdot$ R. Ebinghaus Institute of Coastal Research, Helmholtz-Zentrum Geesthacht, Centre for Materials and Coastal Research, Max-Planck-Strasse 1, Geesthacht 21502, Germany

\section{G. Zhang}

State Key Laboratory of Organic Geochemistry, Guangzhou Institute of Geochemistry, Chinese Academy of Sciences,

Guangzhou 510640, China

\section{Present Address:}

A. Möller

GBA Gesellschaft für Bioanalytik mbH, Goldtschmidtstraße 5,

21073 Hamburg, Germany pentachloroanisole were detected in more than $60 \%$ of the samples. Dicofol was the predominant compound with concentrations mostly higher than $100 \mathrm{pg} / \mathrm{g}$ dry weight $(\mathrm{dw})$ with the highest concentration of $18,000 \mathrm{pg} / \mathrm{g} \mathrm{dw}$. Concentrations of other compounds were mainly below $100 \mathrm{pg} / \mathrm{g} \mathrm{dw}$. CUP levels were much lower than the sediment screening benchmark calculated. The highest levels of $\alpha$-endosulfan, endosulfan sulfate, trifluralin, and chlorpyrifos existed at Laizhou Bay, whereas pentachloroanisole and dicofol had highest mean concentrations at Jiaozhou Bay. Generally, no correlation between pesticide concentrations and total organic carbon was observed either for offshore samples or for near-shore samples.

Keywords Current-use pesticides · Bohai Sea - Yellow Sea Sediment

\section{Introduction}

A large quantity of pesticides is used to control weeds, diseases, or insects and parts of these chemicals are entering into the environment and ecosystem inevitably. For example, it was reported that over two million tons of pesticides are used in agriculture worldwide every year (USEPA 2011). Some pesticides pose risk to both humans and sensitive ecosystems and are undergoing regional even global transport for their persistence in the environment and semivolatile property (Wania et al. 1998; Hoferkamp et al. 2010). Due to the properties of persistence, bioaccumulation, adverse effects including human and ecotoxicity, as well as potential for long-range transport (LRT), a dozen of pesticides are listed as persistent organic pollutants (POPs) under the Stockholm Convention and are banned for agricultural use worldwide (www.pops.int). However, some of the current-use pesticides possess parts of the POPs' properties and are still in use widely around the world and thus are of great concern. 
After released into the environment, pesticides undergo a series of physicochemical processes and can transport to coastal and marine environment and even the polar region through riverine discharge and atmospheric transport (Hoferkamp et al. 2010). Through atmospheric transport, these chemicals reach seawater via dry deposition, wet deposition, and air-sea gas exchange (Bidleman and McConnell 1995; Bidleman 1999). Once they reached seawater, pesticides can undergo sedimentation processes by absorbing on particles and/ or can be transported to the deep sea or ocean far away from their source regions (Dachs et al. 1996, 2002). Pesticides associated with sediment would be bioaccumulated by benthic invertebrates, which play a key role in the transfer of aquatic contaminants to higher trophic levels (Reynoldson 1987; DiPinto 1996). Re-emission of pesticides from sediment/surface seawater could happen since primary emission dramatically decreases or ceases (e.g., in the case of a global ban of use), making the ocean as secondary sources of pesticides (Lohmann et al. 2007; Breivik et al. 2004).

China is the largest producer and user of pesticide in the world. Until 2008, more than 600 pesticide active ingredients are produced in China with a production of approximately one million tons/year (He 2008). From January to November 2012, the total production of pesticides was 3.2 million tons in China, while the pesticide market demands for 2013 in China were estimated to be around 1 million tons (Shu and Zhao 2013). In the past 20 years, investigations on legacy organochlorine pesticides (OCPs) (such as dichlorodiphenyltrichloroethanes (DDTs) and hexachlorocyclohexanes (HCHs)) in China's coastal environment have been well documented, and the levels, distributions, and sources of legacy OCPs in sediment and biota samples and their risk assessments were widely reported (Zhang et al. 2002, 2009; Yang et al. 2005; Hu et al. 2009). However, there are few studies on the occurrence of CUPs (mainly focusing on organophosphorous and pyrethroid insecticides) in the terrestrial and coastal water samples and urban waterway sediment samples (Zhang et al. 2002; Mehler et al. 2011; Wang et al. 2012a). CUPs in coastal sediment samples were rarely reported, especially for the open sea region.

In the present study, surface sediments from the Bohai and Yellow seas were analyzed for six CUPs (trifluralin, dacthal, quintozene, endosulfan, chlorpyrifos, and dicofol) and two metabolites (pentachloroanisole and endosulfan sulfate). The physicochemical properties of these target compounds are given in Table 1. Surveys and long-term monitoring studies have demonstrated the presence of these CUPs in the Arctic environment (Hoferkamp et al. 2010; Zhong et al. 2012a), which suggests the potential

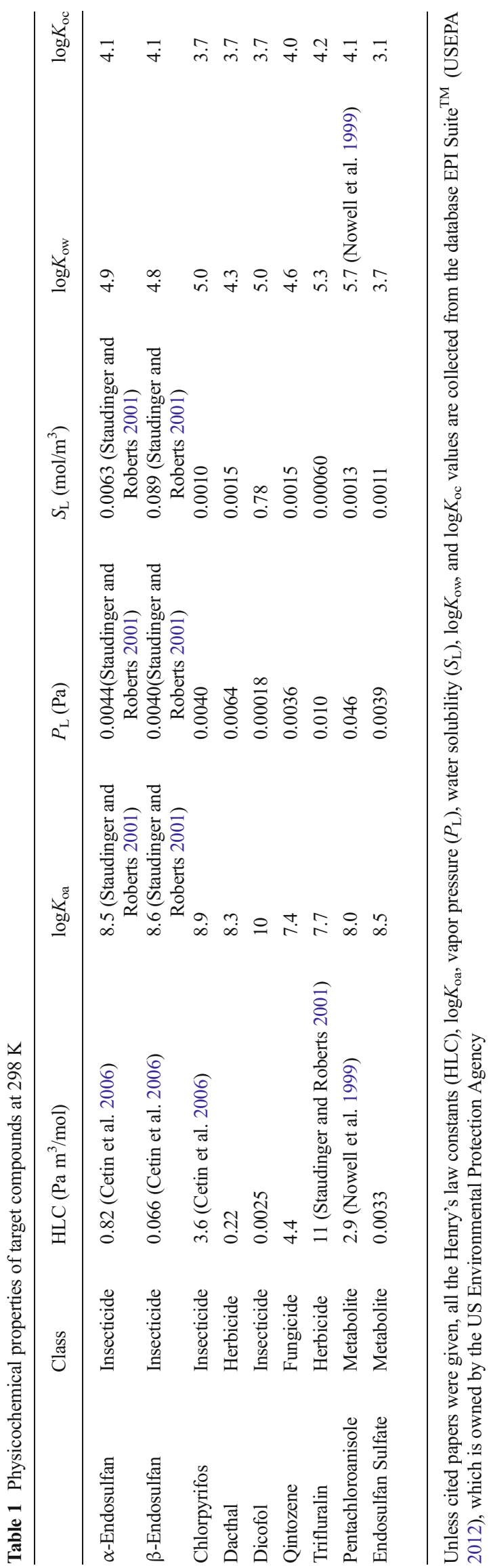


for long-range transport. Trifluralin, dacthal, endosulfan, chlorpyrifos, and dicofol also have been detected in marine air and seawater of East Asia (Zhong et al. 2012a). The Bohai and Yellow seas border on important agricultural regions (Liaoning, Hebei, Shandong, and Jiangsu provinces and Tianjin Municipality) of China, and these regions account for $6 \%$ of the total land area of China but $23.5 \%$ of the total pesticide consumption of the country (www.stats.gov.cn). Jiangsu and Shandong provinces were the first and second largest pesticide producers of China in 2011, of which they account for 29 and $20 \%$ of the total production, respectively (www. chinapesticide.gov.cn). Several important rivers with huge amounts of runoff and sediment load are emptying into the Bohai and Yellow seas, including Liaohe River (drainage area $2.2 \times 10^{5} \mathrm{~km}^{2}$ ), Haihe River (drainage area $2.7 \times 10^{5} \mathrm{~km}^{2}$ ), Yellow River (drainage area $7.5 \times 10^{5} \mathrm{~km}^{2}$ ), and Yangtze River (drainage area $1.8 \times 10^{6} \mathrm{~km}^{2}$ ). Concentrations, distributions, and potential ecological risk of these CUPs in Bohai and Yellow sea sediments are discussed in this paper. These results will facilitate further research on the environmental impact and fate of CUPs in these regions.

\section{Materials and methods}

Sample collection

Seventy-two surface sediment samples were collected from the Bohai and Yellow seas with a stainless steel grab sampler in September 2009 for Laizhou Bay at the south of Bohai Sea (top $10 \mathrm{~cm}$ sediment collected) and with a stainless steel box corer in April 2010 for other sampling areas (top $5 \mathrm{~cm}$ sediment collected). The sediment samples were stored at $-20^{\circ} \mathrm{C}$ prior to freeze-drying. Sampling sites are shown in Fig. 1.

Extraction, clean-up, and analysis

Freeze-dried and homogenized sediments $(10 \mathrm{~g})$ were Soxhlet-extracted with dichloromethane (DCM) for $16 \mathrm{~h}$, and activated granulated copper was used for desulfurization; $500 \mathrm{pg}$ of $\mathrm{d}^{14}$-Trifluralin was added as surrogate before extraction. The extracts were concentrated to $2 \mathrm{~mL}$ using a rotary evaporator and further cleaned on a 2.5 -g $10 \%$ waterdeactivated silica gel (mesh size 70 to 140) column topped with $3 \mathrm{~g}$ anhydrous granulated sodium sulfate. The column was eluted with $20 \mathrm{~mL}$ hexane (fraction 1), followed by

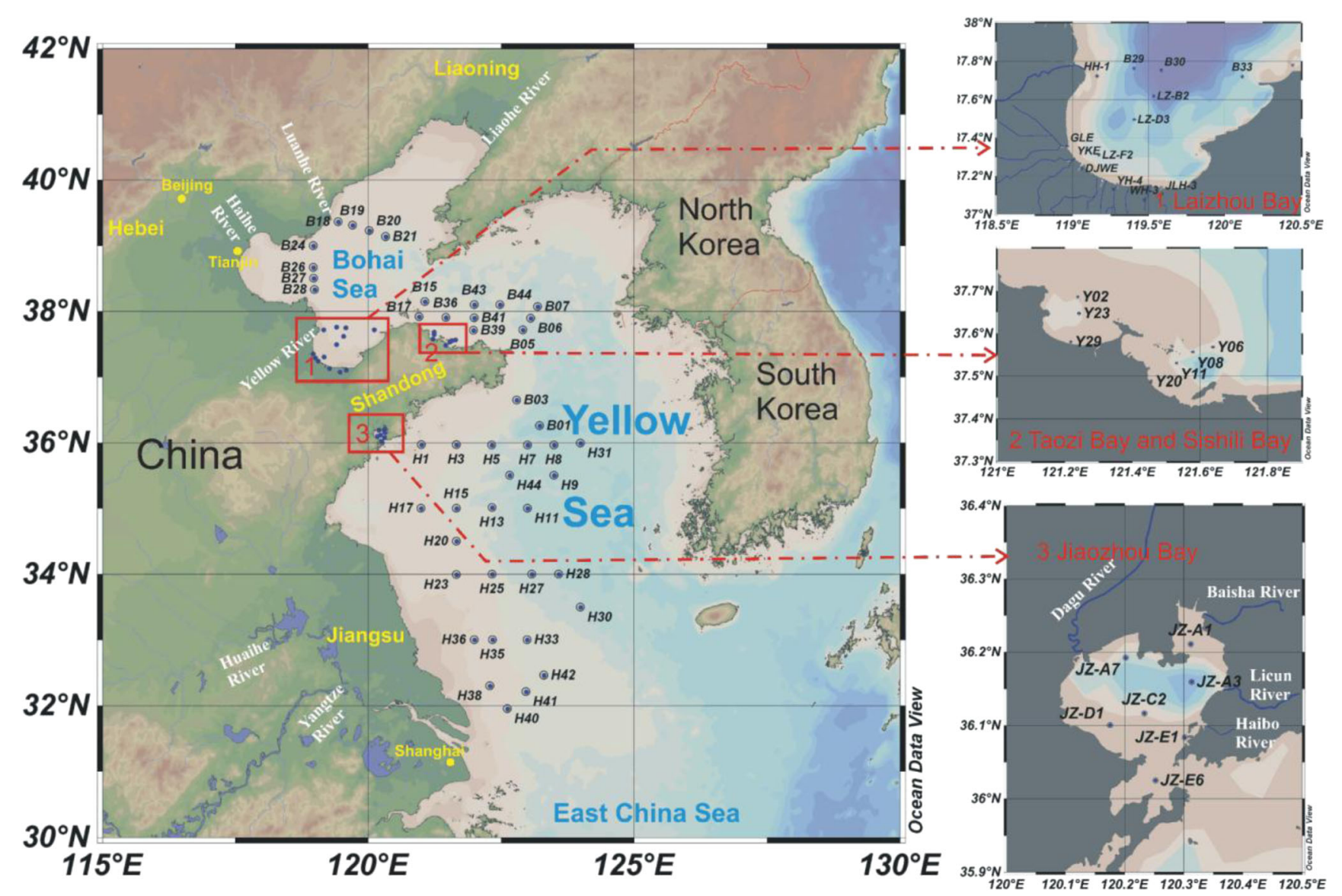

Fig. 1 Location of sampling sites at the Bohai and Yellow seas 
$30 \mathrm{~mL}$ dichloromethane/acetone (1:1) (fraction 2). Each fraction was evaporated to a final volume of $\sim 30 \mu \mathrm{L}$. The solvent of fraction 2 was changed to hexane during evaporation; $500 \mathrm{pg}$ of ${ }^{13} \mathrm{C}-\mathrm{PCB} 141$ was added to both fractions as an internal standard.

Both fractions were analyzed with a GC/MS system $(6890$ GC/5973 MSD) in electron capture negative chemical ionization mode (ECNCI) equipped with an HP-5MS column $(30 \mathrm{~m} \times 0.25 \mathrm{~mm}$ i.d. $\times 0.25 \mu \mathrm{m}$ film thickness, $\mathrm{J} \& \mathrm{~W}$ Scientific). Methane was used as the ionization gas. The injector was operated in pulsed-splitless mode (injection pulse $20 \mathrm{psi}$ for $2 \mathrm{~min}$ ) with an inlet temperature program as follows: $60{ }^{\circ} \mathrm{C}$ for $0.1 \mathrm{~min}$ and $500{ }^{\circ} \mathrm{C} / \mathrm{min}$ until $280^{\circ} \mathrm{C}$ and held for a final $20 \mathrm{~min}$. The $\mathrm{GC}$ oven program was as follows: initial $60{ }^{\circ} \mathrm{C}$ for $2 \mathrm{~min}, 30{ }^{\circ} \mathrm{C} / \mathrm{min}$ until $150{ }^{\circ} \mathrm{C}, 2{ }^{\circ} \mathrm{C} / \mathrm{min}$ until $240{ }^{\circ} \mathrm{C}$, and $20^{\circ} \mathrm{C} / \mathrm{min}$ until $300^{\circ} \mathrm{C}$ and held for $5 \mathrm{~min}$. The temperature of the MS transfer line was held at $280{ }^{\circ} \mathrm{C}$. The ion source and quadrupole temperature was $150{ }^{\circ} \mathrm{C}$. Total amounts of individual compounds in the samples are the sum of fractions 1 and 2.

\section{Quality assurance and quality control}

One method blank was run for each batch of samples extracted (12 samples per batch) and six method blanks were obtained in total for the 72 samples extracted. Mean absolute blank values of CUPs ranged from 0.27 to $14 \mathrm{pg}$. Method detection limits (MDLs) were derived from mean field blank values plus three times the standard deviation $(\sigma)$ (for compounds not present in the field blanks), then instrumental detection limits at a signal-to-noise ratio of three were used instead. Using a mean sediment sample mass of $10 \mathrm{~g}$, the MDLs ranged from 0.067 to $2.6 \mathrm{pg} / \mathrm{g}$. Concentrations calculated from $\mathrm{GC} / \mathrm{MS}$ signals which were below the MDLs were defined as not detected in this work. The spike test recoveries for $\alpha$ endosulfan, $\beta$-endosulfan, endosulfan sulfate, trifluralin, pentachloroanisole, quintozene, dicofol, chlorpyrifos, and dacthal were $66 \pm 4,96 \pm 7,65 \pm 67,58 \pm 8,49 \pm 3,58 \pm 4,123$ $\pm 27,51 \pm 28$, and $109 \pm 9 \%$, respectively. Surrogate recoveries in this study were $52 \pm 19 \%$. Therefore, the analysis of CUPs in this study was semiquantitative. The concentrations were corrected with surrogate recoveries. Namely, the concentrations calculated from GC/MS signals are divided by the surrogate $\left(\mathrm{d}^{14}\right.$-Trifluralin) recovery to get the reported concentrations in this paper. Details of MDLs, spike test recoveries, and surrogate recoveries are provided in Tables $\mathrm{S} 1$ and $\mathrm{S} 2$ in the Supplementary material.

Total organic carbon (TOC) analysis

Total organic carbon of freeze-dried powdered sediments was determined by a $\mathrm{LECO}^{\circledR}$ RC612 multiphase carbon and hydrogen/moisture analyzer. Total organic carbon is analyzed by placing approximately $0.20 \mathrm{~g}$ of dried, ground, and homogenized sediment sample into a clean, carbon-free combustion boat. The sample is placed into an oven set at $60{ }^{\circ} \mathrm{C}$ and then combusted at $550{ }^{\circ} \mathrm{C}$ until no more $\mathrm{CO}_{2}$ is created ( $\sim 15 \mathrm{~min}) . \mathrm{CO}_{2}$ from the combustion is quantified by infrared detection and used to estimate TOC. TOCs for sediments in this study range from 0.035 to $1.3 \%$ (average $0.54 \pm 0.33 \%$ ). TOCs of individual sampling sites were provided in Table S2 in the Supplementary material. Pearson correlation between TOC and pesticide concentrations was performed using the program SPSS 16.0 for Windows (SPSS Inc., Chicago, IL).

\section{Results and discussion}

\section{Concentrations}

Concentrations (dry weight, $\mathrm{dw}$ ) for individual sampling sites were listed in detail in Table S2. The sampling sites were classified into two groups (Table S2), namely near-shore samples along the coast of Shandong Peninsula (Laizhou Bay, Taozi Bay, Sishili Bay, and Jiaozhou Bay) and the offshore samples.

$\alpha$-Endosulfan, endosulfan sulfate, trifluralin, chlorpyrifos, dicofol, and pentachloroanisole were the most frequently detected compounds with $60 \%$ of the samples detected. $\beta$ Endosulfan, dacthal, and quintozene were detected in 36, 17, and $7 \%$ of the samples, respectively. Dicofol was the predominant compound with $\sim 90 \%$ of the concentration values larger than $100 \mathrm{pg} / \mathrm{g}$, followed by chlorpyrifos, with a maximum level of $140 \mathrm{pg} / \mathrm{g} \mathrm{dw}$. Other compounds had maximum concentrations around $10 \mathrm{pg} / \mathrm{g} \mathrm{dw}$. The levels of the target compounds (excluding dicofol) in surface sediments (ranging from 0.0050 to $140 \mathrm{pg} / \mathrm{g}$ ) were lower than previously reported levels of legacy OCPs, i.e., HCHs and DDTs (160-5,700 pg/ g), while these two pesticides accounted for about $78 \%$ of the total pesticide production and usage in China during the 1960s to 1983 (Hu et al. 2009).

The levels of dicofol in the Bohai and Yellow sea sediments spanned a wide range from 0.30 to $18,000 \mathrm{pg} / \mathrm{g}$ dw with an average of $1,300 \pm 2,500 \mathrm{pg} / \mathrm{g} \mathrm{dw}$. Dicofol is a broad spectrum insecticide with excellent efficacy. It is widely used for mites control on a wide variety of fruits and crops. Dicofol has been produced in China since 1976 and its production in China was estimated to be 3,500 tons per year in recent years (Project Document for China Dicofol Project 2008). Dicofol contains DDT as an impurity, since it is mainly synthesized from DDT. It is widely accepted that dicofol usage is an important current source of DDT in China (Qiu et al. 2005; Yang et al. 2008), while only a few studies focus on dicofol itself. Xue et al. analyzed dicofol in water and sediment of the Beijing Guanting Reservoir and reported a mean concentration of 49 $\pm 15 \mathrm{pg} / \mathrm{g} \mathrm{dw}$ (Xue et al. 2005). The relatively high 
concentrations of dicofol in the present study indicate that the occurrence of dicofol in China's coastal environment deserve more attention.

The predominance of dicofol in the Bohai and Yellow seas could be attributed to its high consumption volume and physicochemical properties. The $\log K_{\mathrm{oc}}$ values can be used to estimate the sorption of hydrophobic pollutants on natural sediments. Among target compounds, dicofol has a relatively low $\log K_{\mathrm{oc}}$ value (Table 1 ), suggesting its weak partitioning in sediment. However, it has the lowest Henry's law constant or the largest water solubility (Table 1), which could lead to relatively high dicofol concentrations in seawater due to stronger net deposition during air-seawater gas exchange or greater input of dicofol via riverine transport. Thus, the relatively high concentrations of dicofol in sediment samples resulted from its low Henry's law constant or high water solubility rather than its $\log K_{\mathrm{oc}}$. This explanation is supported by the results from our recent study on CUPs in the air and seawater of the Bohai and Yellow seas. Dicofol was found to have low concentrations in the air but relative enrichment in seawater compared with other CUPs with higher Henry's law constant or lower water solubility (Zhong et al. 2014).

Endosulfan has been agriculturally used in China since 1994. It has been listed in Annex A of the Stockholm Convention in May 2011 (UNEP 2013), and new registrations of endosulfan-based products in China are prohibited since July 2011 (MOA 2011). The total usage of endosulfan on cotton, wheat, tea, tobacco, and apples in China was estimated to be 25,700 tons between 1994 and 2004 within the regions of Hebei, Shandong, and Jiangsu provinces, and the coasts of Bohai and Yellow seas were the regions of most intensive endosulfan usage (Jia et al. 2009). Technical grade endosulfan contains two isomers, known as $\alpha$-endosulfan and $\beta$ endosulfan. The $\alpha-/ \beta$-endosulfan isomer ratio ranges from
2.0 to 2.3 depending on the technical mixture (Herrmann 2002). Endosulfan is subject to degradation in aquatic systems and the main metabolite in sediments is endosulfan sulfate (Weber et al. 2010). In this study, endosulfan sulfate accounted for $60 \pm 22 \%$ of total endosulfans (sum of $\alpha$ endosulfan, $\beta$-endosulfan, and endosulfan sulfate) (Table S2), indicating a significant degradation of endosulfan in the sediments of Bohai and Yellow seas.

$\alpha$-Endosulfan, $\beta$-endosulfan, and endosulfan sulfate in our study had maximum levels of around $20 \mathrm{pg} / \mathrm{g}$ dw (Table S2), which were lower than the reported levels of these compounds in the surface sediments collected in 2006 in the Bohai Sea (30 to $700 \mathrm{pg} / \mathrm{g} \mathrm{dw}$ ) (Hu et al. 2009). Lin et al. (2012) analyzed endosulfan in surface sediments from the coast of East China Sea in 2007 and found that both endosulfan isomers were detected only in few sediment samples (Lin et al. 2012). Comparison of endosulfan concentrations in coastal sediment samples from different areas in the world is given in Table 2. Endosulfan concentrations in our study are at similar levels as those for the Persian Gulf, Gulf of Oman, and coast of Campeche, Mexico (de Mora et al. 2005; Carvalho et al. 2009a), but lower than those observed in sediments from the Portuguese coast, three estuaries of the Cantabrian Coast, Spain (Carvalho et al. 2009b; Gomez et al. 2011), as well as the Daliao River Estuary, and Yangtze River Estuary, China (Tan et al. 2009; Liu et al. 2003).

In this study, concentration ranges for both endosulfan isomers were comparable (Table 2), but the ratios of $\alpha-/ \beta$ endosulfan spanned wide ranging from 0.0086 to 23 with $60 \%$ of the values lower than the ratios for technical mixtures (2.0-2.3). Previously reported $\alpha$-/ $\beta$-isomer ratios $(0.3$ to 1.8$)$ for Bohai Sea surface sediments in 2006 were also lower than those for technical mixtures, but the ratios were within a smaller range (Hu et al. 2009). Estimated $K_{\mathrm{oc}}$ values of the

Table 2 The range of endosulfans' concentrations (in $\mathrm{pg} / \mathrm{g} \mathrm{dw}$ ) in marine sediments of different areas in the world

\begin{tabular}{|c|c|c|c|c|c|}
\hline Sampling areas & $\begin{array}{l}\text { Sampling } \\
\text { year }\end{array}$ & $\alpha$-Endosulfan & $\beta$-Endosulfan & $\begin{array}{l}\text { Endosulfan } \\
\text { sulfate }\end{array}$ & Reference \\
\hline Bohai and Yellow Seas & 2010 & $<0.0082$ to 22 & $<0.0066$ to 17 & 0.0081 to 18 & This study \\
\hline Bohai Sea & 2006 & $<30$ to 730 & $<30$ to 400 & $<30$ to 560 & Hu et al. (2009) \\
\hline East China Sea & 2007 & Detected in few samples ${ }^{\mathrm{a}}$ & Detected in few samples ${ }^{\mathrm{a}}$ & No data & Lin et al. (2012) \\
\hline $\begin{array}{l}\text { Coast of Persian Gulf and Gulf } \\
\text { of Oman }\end{array}$ & 2000 and 2001 & $<0.2$ to 16 & $<0.95$ to 29 & $<1.3$ to 11 & de Mora et al. (2005) \\
\hline Coast of Campeche, Mexico & 2000 & $<0.55$ & $<0.65$ to 7.2 & No data & Carvalho et al. (2009a) \\
\hline Coast of Portugal & 2007 and 2008 & 680 to 5,900 & No data & No data & Carvalho et al. (2009b) \\
\hline $\begin{array}{l}\text { Three estuaries in the Cantabrian } \\
\text { Coast, Spain }\end{array}$ & 2006 & 200 to 600 & $<210$ to 400 & $<170$ & Gomez et al. (2011) \\
\hline Daliao River Estuary, Bohai Sea & 2007 & 10 to 200 & 10 to 800 & No data & Tan et al. (2009) \\
\hline $\begin{array}{l}\text { Yangtze Estuary and nearby } \\
\text { coastal areas, China }\end{array}$ & 2001 & $<30$ to 1,230 & $<100$ to 160 & No data & Liu et al. (2003) \\
\hline
\end{tabular}

In this table, samples in which endosulfans were not detectable are excluded when we summarize the range of concentrations

${ }^{a}$ Details are not given in this paper 
$\alpha$ - and $\beta$-isomer are the same (Table 1). However, $\alpha$ endosulfan has greater tendency of volatility from both solid and aqueous surfaces than the $\beta$-isomer (Antonious et al. 1998). Moreover, isomeric conversion from $\beta$-endosulfan to $\alpha$-endosulfan has been demonstrated to occur in the environment (Schmidt et al. 1997; Walse et al. 2002). These are the possible reasons that high ratios of $\alpha-\beta$-endosulfan were observed. However, remobilization experiments showed that $\alpha$-endosulfan desorbed more readily from sediments than the $\beta$-isomer (Peterson and Batley 1993) and the $\alpha$-isomer is converted more readily to endosulfan sulfate than the $\beta$ isomer (Leonard et al. 2001; Walse et al. 2003). A combined influence of the factors mentioned above may explain the wide range of $\alpha$ - $/ \beta$-endosulfan ratios.

Pentachloroanisole is a metabolite of quintozene and pentachlorophenol (PCP) (China Pesticide Information 2012). In our study, detection frequency and concentrations of pentachloroanisole were higher than those of qintozene. Much higher concentrations of pentachloroanisole than those of quintozene were also observed in the air and seawater samples of the German Bight (North Sea) in our previous work (Zhong et al. 2012b). Domestic consumption of quintozene is estimated to be 32 tons per year (Wang et al. 2012b). Annual production of PCP together with pentachlorophenol-Na (Na-PCP) ranged from 1,000 to 10,000 tons during 1983 to 2003, but PCP production was discontinued in 1995 and Na-PCP was produced until 2003 (Wang et al. 2010). The much higher concentrations of pentachloroanisole compared with quintozene possibly resulted from the significant degradation of quintozene and additional pentachloroanisole contribution from the degradation of PCP.

Chlorpyrifos had the second highest concentrations in the sediments of Bohai and Yellow seas and this is possibly attributed to its relatively high consumption volume in recent years. The domestic market demand of chlorpyrifos was 18,000 tons in 2008 (http://www.ccpia.com.cn/, China Crop Protection Industry Association). Trifluralin is expected to be prone to accumulation in sediments, since it has a relatively high $\log K_{\mathrm{oc}}$ value of 4.2. However, high Henry's law constant (Table 1) might result in its low partitioning in seawater during air-water gas exchange, thereby going against its enrichment in sediment. Dacthal had low detection frequency in sediments of Bohai and Yellow seas, whereas it was one of the most abundant CUPs in the air of the Centre Region (France) and North America (Kuang et al. 2003; Peck and Hornbuckle 2005; Brun et al. 2008; Yusa et al. 2010). This result is consistent with the fact that dacthal has not been registered in China (China Pesticide Information 2012).

\section{Spatial distributions}

Spatial distributions of compounds with high detection frequencies (>60\%), namely dicofol, $\alpha$-endosulfan, trifluralin, chlorpyrifos, pentachloroanisole, and endosulfan sulfate, are discussed below. Generally, the highest mean concentrations appeared at near-shore sampling sites (Table S2). For instance, the highest mean concentrations of $\alpha$-endosulfan, endosulfan sulfate, trifluralin, and chlorpyrifos were found in Laizhou Bay, whereas pentachloroanisole and dicofol had the highest mean concentrations in Jiaozhou Bay. Sampling sites with high concentrations were generally at/close to estuaries. Relatively high-contaminated near-shore sites of Laizhou Bay were DJWE where high levels of chlorpyrifos, dicofol, $\alpha$-endosulfan, trifluralin, and pentachloroanisole were detected and YKE where high levels of trifluralin, chlorpyrifos, and dicofol were detected (Fig. 2). Similarly, the highest chlorpyrifos levels occurred close to the Baisha River and Haibo River estuaries (JZ-A1 and JZ-E1) and the highest dicofol levels were found close to Licun River and Haibo River estuaries (JZ-A3 and JZ-E1) in Jiaozhou Bay (Fig. 2). For the offshore sampling sites, mean concentrations of most compounds at the Bohai Sea were higher than those at the Yellow Sea.

Spatial distributions of hydrophobic pollutants in sediments can significantly correlate with the distributions of TOC due to the post-depositional sorption or co-emission (Hung et al. 2006). Good correlations between hydrophobic pollutants and TOC are supposed to be observed in offshore areas and continental shelf, since these relatively homogeneous environmental conditions provide a TOC-dependent post-depositional sorption environment (Lee et al. 2001; Zhang et al. 2007).

In this work, a correlation between concentrations and TOC was basically not observed for offshore samples (Table S3). This result may be due to the fresh input of these compounds. Previous studies showed good correlations between TOC and legacy organochlorines for the sediments of Bohai and Yellow seas (Zhang et al. 2007; Hu et al. 2009). The restriction of use of organochlorines (for examples, DDTs, HCHs, hexachlorobenzene, and polychlorinated biphenyls) would favor a post-depositional sorption-dominated distribution of these chemicals in offshore sediments because of a lack of fresh inputs, which could give rise to the possibility of a concentration distribution inconsistent with the TOC distribution.

A correlation between concentrations and TOC was generally not found for near-shore sampling sites too, except that pentachloroanisole and dicofol concentrations significantly correlated with TOC at Jiaozhou Bay $(r=0.957, p=0.003$ for pentachloroanisole and $r=0.883, p=0.009$ for dicofol). This result suggests spatially limited or defined sources near the coast. For instance, Zhong et al. (2011) reported good correlations between legacy OCPs and TOC for offshore sediments of Laizhou Bay but not for adjacent estuarine and riverine sediments, some of which especially high OCP concentrations were detected (Zhong et al. 2011). A lack of correlation between legacy OCPs and TOC was also observed for coastal 


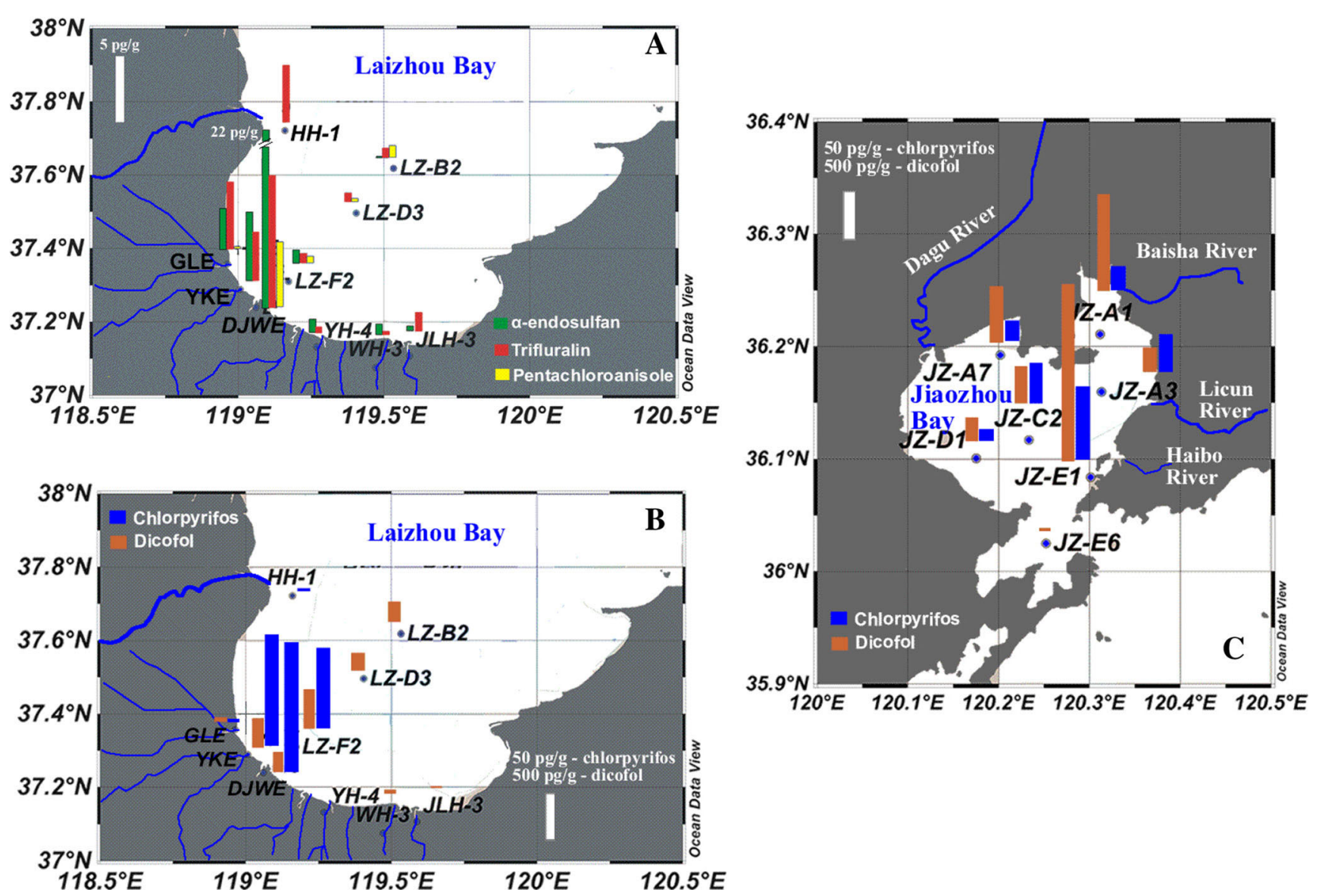

Fig. 2 Distributions of $\alpha$-endosulfan, trifluralin, and pentachloroanisole in Laizhou Bay (a) and distributions of dicofol and chlorpyrifos in Laizhou Bay (b) and Jiaozhou Bay (c)

East China Sea sediments, and high HCH and DDT concentrations, respectively, existed at the estuaries and in the nearshore area with a significant decrease gradient seaward owing to nonpoint sources of the coast (Lin et al. 2012).

Evaluation of ecological effects

Ecological effects of CUPs in sediment can be preliminarily evaluated by comparing CUP concentrations in the present study with sediment screening benchmarks. However, sediment screening benchmarks of the six frequently detected CUPs are unavailable. Sediment screening benchmarks can be estimated from water screening benchmarks using the equilibrium partitioning approach by Di Toro et al. (1991):

$\mathrm{SSB}=\mathrm{WSB} \times K_{\mathrm{oc}} \times f_{\mathrm{oc}} / 100$

where SSB is the sediment screening benchmark ( $\mu \mathrm{g} / \mathrm{g})$, WSB is the water screening benchmarks $(\mu \mathrm{g} / \mathrm{L})$, and $f_{\text {oc }}$ is the TOC content of the sediment samples (\%). Marine water screening benchmarks for chlorpyrifos, $\alpha$-endosulfan, and endosulfan sulfate are 0.0056, 0.0010, and $0.009 \mu \mathrm{g} / \mathrm{L}$, respectively (EPA
Region 3 Ecological Risk Assessment, www.epa.gov). Marine water screening benchmarks are unavailable for dicofol, trifluralin, and pentachloroanisole, so freshwater screening benchmarks were used instead, i.e., $19.8 \mu \mathrm{g} / \mathrm{L}$ for dicofol (Texas Surface Water Quality Standards, www.tceq. state.tx.us), $0.2 \mu \mathrm{g} / \mathrm{L}$ for trifluralin (EPA Region 3 Ecological Risk Assessment, www.epa.gov), and unavailable for pentachloroanisole. CUP concentrations in our study are much lower than the resulting sediment screening benchmarks for chlorpyrifos, $\alpha$-endosulfan, endosulfan sulfate, dicofol, and trifluralin, which are at the microgram per gram level $(0.0044-1,300 \mu \mathrm{g} / \mathrm{g})$.

\section{Conclusion}

Six current-use pesticides and two of their metabolites were detected in the coastal and offshore sediments of Bohai and Yellow seas, and lower concentrations of CUPs (except dicofol) than legacy OCPs previously reported were found. Dicofol had relatively high concentrations compared with the other compounds and especially high levels were observed at Jiaozhou Bay. The high levels of dicofol in sediments can be 
attributed to its high consumption amount recently, together with its low Henry's law constant and high solubility in water. The occurrence and fate of dicofol in the aquatic environment deserves further research. Concentrations of endosulfan sulfate were higher than its parent compounds (i.e., $\alpha$-endosulfan and $\beta$-endosulfan). This case is expected to be continued, since endosulfan has been listed in the Stockholm Convention and its primary emissions are expected to decrease. High concentrations of the compounds generally occurred at near-shore sampling sites especially at sampling sites at/close to estuaries. It can be explained by the riverine input nearby, since a correlation between concentrations and TOC was not found, except for pentachloroanisole and dicofol at Jiaozhou Bay.

Acknowledgment This study was financially supported by the Chinese Academy of Sciences (KZCX2-EW-QN210, KZZD-EW-14, and YZ201161) and the National Natural Science Foundation of China (40933048 and 41073064). We are grateful for the field assistance from the crew of Research Vessel Dongfanghong 2 of the Ocean University of China.

\section{References}

Antonious GF, Byers ME, Snyder JC (1998) Residues and fate of endosulfan on field-grown pepper and tomato. Pestic Sci 54(1):61-67. doi:10.1002/(sici)1096-9063(199809)54:1<61::aid-ps780>3.0. co; $2-\mathrm{m}$

Bidleman T (1999) Atmospheric transport and air-surface exchange of pesticides. Water Air Soil Pollut 115(1-4):115-166. doi:10.1023/ A: 1005249305515

Bidleman TF, McConnell LL (1995) A review of field experiments to determine air-water gas exchange of persistent organic pollutants. Sci Total Environ 159(2-3):101-117. doi:10.1016/0048-9697(95) 04255-Y

Breivik K, Alcock R, Li YF, Bailey RE, Fiedler H, Pacyna JM (2004) Primary sources of selected POPs: regional and global scale emission inventories. Environ Pollut 128(1-2):3-16. doi:10.1016/j. envpol.2003.08.031

Brun GL, MacDonald RM, Verge J, Aube J (2008) Long-term atmospheric deposition of current-use and banned pesticides in Atlantic Canada; 1980-2000. Chemosphere 71(2):314-327. doi:10.1016/j. chemosphere.2007.09.003

Carvalho FP, Villeneuve JP, Cattini C, Rendon J, de Oliveira JM (2009a) Pesticide and PCB residues in the aquatic ecosystems of Laguna de Terminos, a protected area of the coast of Campeche, Mexico. Chemosphere 74(7):988-995. doi:10.1016/j.chemosphere.2008.09. 092

Carvalho PN, Rodrigues PNR, Basto MCP, Vasconcelos MTSD (2009b) Organochlorine pesticides levels in Portuguese coastal areas. Chemosphere 75(5):595-600. doi:10.1016/j.chemosphere.2009.01. 060

Cetin B, Ozer S, Sofuoglu A, Odabasi M (2006) Determination of Henry's law constants of organochlorine pesticides in deionized and saline water as a function of temperature. Atmos Environ 40(24):4538-4546. doi:10.1016/j.atmosenv.2006.04.009

China Pesticide Information Network (2012) http://www.chinapesticide. gov.cn/. Accessed June 4
Dachs J, Bayona JM, Fowler SW, Miquel JC, Albaiges J (1996) Vertical fluxes of polycyclic aromatic hydrocarbons and organochlorine compounds in the western Alboran Sea (southwestern Mediterranean). Mar Chem 52(1):75-86. doi:10.1016/0304-4203(95)00084-4

Dachs J, Lohmann R, Ockenden WA, Mejanelle L, Eisenreich SJ, Jones KC (2002) Oceanic biogeochemical controls on global dynamics of persistent organic pollutants. Environ Sci Technol 36(20):42294237. doi:10.1021/Es025724k

de Mora S, Fowler SW, Tolosa I, Villeneuve JP, Cattini C (2005) Chlorinated hydrocarbons in marine biota and coastal sediments from the Gulf and Gulf of Oman. Mar Pollut Bull 50(8):835-849. doi:10.1016/j.marpolbul.2005.02.022

DiPinto LM (1996) Trophic transfer of a sediment-associated organophosphate pesticide from meiobenthos to bottom feeding fish. Arch Environ Contam Toxicol 30(4):459-466

Di Toro DM, Zarba CS, Hansen DJ, Berry WJ, Swartz RC, Cowan CE, Pavlou SP, Allen HE, Thomas NA, Paquin PR (1991) Technical basis for establishing sediment quality criteria for nonionic organic chemicals using equilibrium partitioning. Environ Toxicol Chem 10:1541-1583

Gomez S, Gorri D, Irabien A (2011) Organochlorine pesticide residues in sediments from coastal environment of Cantabria (northern Spain) and evaluation of the Atlantic Ocean. Environ Monit Assess 176(14):385-401. doi:10.1007/s10661-010-1591-4

He HW (2008) The use of OP and development of new organophosphorus agrochemicals in China. Phosphorus, Sulfur Silicon Relat Elem 183(2-3):266-279. doi:10.1080/10426500701734232

Herrmann M (2002) Preliminary risk profile of endosulfan. Umweltbundesamt, Berlin Germany

Hoferkamp L, Hermanson MH, Muir DCG (2010) Current use pesticides in Arctic media; 2000-2007. Sci Total Environ 408(15):2985-2994. doi:10.1016/j.scitotenv.2009.11.038

Hu L, Zhang G, Zheng B, Qin Y, Lin T, Guo Z (2009) Occurrence and distribution of organochlorine pesticides (OCPs) in surface sediments of the Bohai Sea, China. Chemosphere 77(5):663-672. doi: 10.1016/j.chemosphere.2009.07.070

Hung CC, Gong GC, Jiann KT, Yeager KM, Santschi PH, Wade TL, Sericano JL, Hsieh HL (2006) Relationship between carbonaceous materials and polychlorinated biphenyls (PCBs) in the sediments of the Danshui River and adjacent coastal areas, Taiwan. Chemosphere 65(9):1452-1461. doi:10.1016/j.chemosphere.2006.04.037

Jia HL, Li YF, Wang DG, Cai DJ, Yang M, Ma JM, Hu JX (2009) Endosulfan in China 1-gridded usage inventories. Environ Sci Pollut R 16(3):295-301. doi:10.1007/s11356-008-0042-Z

Kuang ZH, McConnell LL, Torrents A, Meritt D, Tobash S (2003) Atmospheric deposition of pesticides to an agricultural watershed of the Chesapeake Bay. J Environ Qual 32(5):1611-1622

Lee KT, Tanabe S, Koh CH (2001) Distribution of organochlorine pesticides in sediments from Kyeonggi Bay and nearby areas, Korea. Environ Pollut 114(2):207-213

Leonard AW, Hyne RV, Lim RP, Leigh KA, Le J, Beckett R (2001) Fate and toxicity of endosulfan in Namoi River water and bottom sediment. J Environ Qual 30(3):750-759

Lin T, Hu L, Shi X, Li Y, Guo Z, Zhang G (2012) Distribution and sources of organochlorine pesticides in sediments of the coastal East China Sea. Mar Pollut Bull 64(8):1549-1555

Liu M, Yang Y, Hou L, Xu S, Ou D, Zhang B, Liu Q (2003) Chlorinated organic contaminants in surface sediments from the Yangtze Estuary and nearby coastal areas, China. Mar Pollut Bull 46(5):672-676. doi:10.1016/S0025-326x(03)000500-X

Lohmann R, Breivik K, Dachs J, Muir D (2007) Global fate of POPs: current and future research directions. Environ Pollut 150(1):150 165. doi:10.1016/j.envpol.2007.06.051

Mehler WT, Li HZ, Lydy MJ, You J (2011) Identifying the causes of sediment-associated toxicity in urban waterways of the Pearl River Delta, China. Environ Sci Technol 45(5):1812-1819. doi:10.1021/ Es103552d 
MOA (2011) Announcement No. 1586. Ministry of Agriculture of the People's Republic of China. http://www.moa.gov.cn/zwllm/tzgg/gg/ 201107/t20110705 2045813.htm. Accessed November 212013

Nowell LH, Capel PD, Dileanis PD (1999) Pesticides in stream sediment and aquatic biota - distribution, trends and governing factors. CRC, Boca Raton

Peck AM, Hornbuckle KC (2005) Gas-phase concentrations of currentuse pesticides in Iowa. Environ Sci Technol 39(9):2952-2959. doi: 10.1021/es0486418

Peterson SM, Batley GE (1993) The fate of endosulfan in aquatic ecosystems. Environ Pollut 82(2):143-152

Project Document for China Dicofol Project (2008). United Nations Development Programme

Qiu XH, Zhu T, Yao B, Hu JX, Hu SW (2005) Contribution of dicofol to the current DDT pollution in China. Environ Sci Technol 39(12): 4385-4390. doi:10.1021/Es050342a

Reynoldson TB (1987) Interactions between sediment contaminants and benthic organisms. Hydrobiologia 149:53-66. doi:10.1007/ bf00048646

Schmidt WF, Hapeman CJ, Fettinger JC, Rice CP, Bilboulian S (1997) Structure and asymmetry in the isomeric conversion of beta- to alpha-endosulfan. J Agric Food Chem 45(4):1023-1026. doi:10. 1021/jf970020t

Shu F, Zhao Q (2013) Overview of China pesticide market on 2012 and its perspective for 2013. China Plant Protection 33(2):4

Staudinger J, Roberts PV (2001) A critical compilation of Henry's law constant temperature dependence relations for organic compounds in dilute aqueous solutions. Chemosphere 44(4):561-576

Tan L, He MC, Men B, Lin CY (2009) Distribution and sources of organochlorine pesticides in water and sediments from Daliao River estuary of Liaodong Bay, Bohai Sea (China). Estuar Coast Shelf Sci 84(1):119-127. doi:10.1016/j.ecss.2009.06.013

UNEP (2013) The new POPs under the Stockholm Convention. Stockholm Convention. http://chm.pops.int/Implementation/ NewPOPs/ThenewPOPs/tabid/672/Default.aspx. Accessed November 212013

USEPA (2011) Pesticides industry sales and usage: 2006 and 2007 Market Estimates.

USEPA (2012) Estimation Programs Interface Suite ${ }^{\mathrm{TM}}$ for Microsoft ${ }^{\circledR}$ Windows, v 4.00. United States Environmental Protection Agency, Washington, DC, USA

Walse SS, Shimizu KD, Ferry JL (2002) Surface-catalyzed transformations of aqueous endosulfan. Environ Sci Technol 36(22):48464853. doi:10.1021/es0256257

Walse SS, Scott GI, Ferry JL (2003) Stereoselective degradation of aqueous endosulfan in modular estuarine mesocosms: formation of endosulfan gamma-hydroxycarboxylate. J Environ Monit 5(3):373379. doi: $10.1039 / \mathrm{b} 212165 \mathrm{~d}$

Wang G, Lu YL, Han JY, Luo W, Shi YJ, Wang TY, Sun YM (2010) Hexachlorobenzene sources, levels and human exposure in the environment of China. Environ Int 36(1):122-130. doi:10.1016/j. envint.2009.08.005

Wang JZ, Li HZ, You J (2012a) Distribution and toxicity of current-use insecticides in sediment of a lake receiving waters from areas in transition to urbanization. Environ Pollut 161:128-133. doi:10. 1016/j.envpol.2011.10.020
Wang YY, Li FG, Yuan SK (2012b) Brief introduction of domestic and oversea registration and application of quintozene. Agrochemicals $51(1): 3$

Wania F, Haugen J-E, Lei YD, Mackay D (1998) Temperature dependence of atmospheric concentrations of semivolatile organic compounds. Environ Sci Technol 32(8):1013-1021. doi:10.1021/ es970856c

Weber J, Halsall CJ, Muir D, Teixeira C, Small J, Solomon K, Hermanson M, Hung H, Bidleman T (2010) Endosulfan, a global pesticide: a review of its fate in the environment and occurrence in the Arctic. Sci Total Environ 408(15):2966-2984. doi:10.1016/j.scitotenv.2009.10.077

Xue ND, Xu XB, Jin ZL (2005) Screening 31 endocrine-disrupting pesticides in water and surface sediment samples from Beijing Guanting reservoir. Chemosphere 61(11):1594-1606. doi:10.1016/ j.chemosphere.2005.04.091

Yang RQ, Jiang GB, Zhou QF, Yuan CG, Shi JB (2005) Occurrence and distribution of organochlorine pesticides (HCH and DDT) in sediments collected from East China Sea. Environ Int 31(6):799-804. doi:10.1016/j.envint.2005.05.027

Yang XL, Wang SS, Bian YR, Chen F, Yu GF, Gu CG, Jiang X (2008) Dicofol application resulted in high DDTs residue in cotton fields from northern Jiangsu province, China. J Hazard Mater 150(1):9298. doi:10.1016/j.jhazmat.2007.04.076

Yusa V, Coscolla C, Colin P, Yahyaoui A, Petrique O, Mellouki A, Pastor A (2010) Occurrence of currently used pesticides in ambient air of Centre Region (France). Atmos Environ 44(32):3915-3925. doi:10. 1016/j.atmosenv.2010.07.014

Zhang Z, Dai M, Hong H, Zhou JL, Yu G (2002) Dissolved insecticides and polychlorinated biphenyls in the Pearl River Estuary and South China Sea. J Environ Monit 4(6):922-928. doi:10.1039/B206891p

Zhang P, Song JM, Liu ZG, Zheng GX, Zhang NX, He ZP (2007) PCBs and its coupling with eco-environments in Southern Yellow Sea surface sediments. Mar Pollut Bull 54(8):1105-1115. doi:10.1016/ j.marpolbul.2007.05.005

Zhang P, Song JM, Yuan HM (2009) Persistent organic pollutant residues in the sediments and mollusks from the Bohai Sea coastal areas, North China: an overview. Environ Int 35(3):632-646. doi:10.1016/ j.envint.2008.09.014

Zhong GC, Tang JH, Zhao Z, Pan XH, Chen YJ, Li J, Zhang G (2011) Organochlorine pesticides in sediments of Laizhou Bay and its adjacent rivers, North China. Mar Pollut Bull 62(11):2543-2547. doi:10.1016/j.marpolbul.2011.08.018

Zhong G, Xie Z, Cai M, Moller A, Sturm R, Tang J, Zhang G, He J, Ebinghaus R (2012a) Distribution and air-sea exchange of currentuse pesticides (CUPs) from East Asia to the high Arctic Ocean. Environ Sci Technol 46(1):259-267. doi:10.1021/es202655k

Zhong GC, Xie ZY, Moller A, Halsall C, Caba A, Sturm R, Tang JH, Zhang G, Ebinghaus R (2012b) Currently used pesticides, hexachlorobenzene and hexachlorocyclohexanes in the air and seawater of the German Bight (North Sea). Environmental Chemistry 9(4):405414. doi:10.1071/En12065

Zhong GC, Tang JH, Xie ZY, Moller A, Zhao Z, Sturm R, Chen YJ, Tian CG, Pan XH, Qin W, Zhang G, Ebinghaus R (2014) Selected current-use and historic-use pesticides in air and seawater of the Bohai and Yellow Seas, China. Journal of Geophysical Research: under revision 